\title{
NA CONTRAMÃO DO ENSINO MÉDIO INOVADOR: PROPOSTAS DO LEGISLATIVO FEDERAL PARA INCLUSÃO DE DISCIPLINAS OBRIGATÓRIAS NA ESCOLA
}

\author{
Daniela Patti do Amaral* \\ Renato José de Oliveira*
}

\begin{abstract}
RESUMO: A proposta do Ministério da Educação (MEC) para um ensino médio inovador tem como perspectiva estimular as redes estaduais de educação a pensar novas soluçōes que diversifiquem os currículos e promovam articulação interdisciplinar voltada para o desenvolvimento de conhecimentos, saberes, competências, valores e práticas. No presente artigo foram analisadas 15 proposições apresentados na Câmara Federal no período posterior à aprovação da proposta do ensino médio inovador pelo MEC e pelo Conselho Nacional de Educação (CNE). Concluímos que, na contramão de uma proposta inovadora para o ensino médio, o Congresso brasileiro insiste na apresentação de projetos de lei que incluam disciplinas obrigatórias na escola, contemplando diferentes conteúdos, a partir de uma perspectiva fragmentada do currículo.
\end{abstract}

Palavras-chave: Política educacional. Disciplinas escolares. Poder Legislativo.

* Doutora em Educação e professora adjunta da Faculdade de Educação da Universidade Federal do Rio de Janeiro (UfRJ). E-mail: danielapatti.ufrj@gmail.com

** Doutor em Educação e professor associado da Faculdade de Educação da UfrJ. E-mail: rj-oliveira1958@uol.com.br 
Na contramão do ensino médio inovador...

AgAINST THE GRAIN OF INNOVATIVE HIGH SCHOOL:

THE FEDERAL LEGISLATIVE PROPOSALS TO INCLUDE COMPULSORY

DISCIPLINES IN SCHOOLING

\begin{abstract}
MEC's proposal for an innovative high school is to stimulate the state system of education to think about new solutions that diversify the curriculum and to promote interdisciplinary articulations in order to develop knowledge, skills, competencies, values and practices. The present paper examined 15 proposals submitted to Congress after the proposed innovative high school was approved by the MEC and the CNE. It concludes that, against the grain of an innovative proposal for high school, Brazilian Congress insists on submitting bills that include compulsory subjects in schooling, covering different content, from a fragmented view of the curriculum.
\end{abstract}

Key words: Education policy. School disciplines. Legislative power.

\title{
Introdução
}

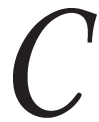

onforme atesta o Ministério da Educação (MEC), o Programa Ensino Médio Inovador surgiu como uma forma de incentivar as redes estaduais de educação a criar iniciativas inovadoras para o ensino médio e pensar novas soluçōes que diversifiquem os currículos com atividades integradoras a partir dos eixos trabalho, ciência, tecnologia e cultura, buscando a melhoria da qualidade da educação oferecida nessa fase de ensino e torná-la mais atraente para os alunos. O Documento Ensino Médio Inovador, elaborado pela Secretaria de Educação Básica do MEC e publicado em abril de 2009, atesta que essa etapa da educação básica tem se constituído, ao longo da história da educação brasileira, como o nível de maior complexidade na estruturação de políticas públicas. Historicamente, o ensino médio oscilou em mostrar diferentes faces: etapa final de escolarização formal; etapa intermediária entre o ensino fundamental e o ensino superior, etapa de consolidação dos saberes construídos no ensino fundamental, formação profissional para diversas áreas do mundo do trabalho e, por fim, mas não menos importante, a face que o caracteriza como refém dos exames vestibulares.

A proposta do MEC para o ensino médio inovador tem cinco questôes centrais a serem discutidas no currículo do ensino médio. A 
primeira é estudar a mudança da carga horária mínima dessa modalidade de ensino para 3 mil horas - um aumento de 200 horas a cada ano. Outra mudança é oferecer ao aluno a possibilidade de escolher $20 \%$ de sua carga horária e grade curricular dentro das atividades oferecidas pela escola. Faz parte ainda da proposta associar teoria e prática, com ênfase em atividades práticas, valorizar a leitura em todas as áreas do conhecimento e garantir formação cultural ao aluno.

A Lei de Diretrizes e Bases da Educação Nacional (Lei n. 9.394/ 96) situa o ensino médio como etapa final da educação básica e o define como a conclusão de um período de escolarização de caráter geral, reconhecendo-o como parte de uma etapa da escolarização que tem por finalidade o desenvolvimento do indivíduo, assegurando-lhe a formação comum indispensável para o exercício da cidadania, fornecendo-lhe os meios para progredir no trabalho e em estudos posteriores (art. 22).

Dados do censo escolar MEC/INEP dos últimos quatro anos mostram estabilidade na oferta de ensino médio, com aumento de 20.515 matrículas em 2010, totalizando 8.357.675 matrículas, correspondendo a $0,2 \%$ a mais que em 2009 . No entanto, o país ainda tem 1,8 milhōes de jovens entre 15 e 17 anos fora da escola. Conforme o Documento Ensino Médio Inovador, o Brasil "massificou o acesso, mas não garantiu democraticamente permanência e, principalmente, um currículo capaz de promover uma aprendizagem que faça sentido para os jovens adolescentes" (p. 5).

Conforme Kuenzer (2010), dos matriculados no ensino médio, apenas 48\% têm entre 15 e 17 anos; esta taxa era de 45,3\% em 2005 e a distorção idade/série cresceu de 0,38 para 0,54 entre 2000 e 2007. Em 2007, 41,3\% das matrículas foram feitas no período noturno, houve crescimento da taxa de repetência de 18,65\% (2000) para 22,6\% em 2005; de evasão, de 8,0\% em 2000, para 10,0\% em 2005 e do tempo médio de conclusão de 3,7\% para 3,8\% no mesmo período.

Assim como em anos anteriores, a rede estadual continua a ser a maior responsável pela oferta de ensino médio e responde por $85,9 \%$ das matrículas. A rede privada atende $11,8 \%$ e as redes federal e municipal atendem pouco mais de $1 \%$ cada.

O Programa Ensino Médio Inovador pretende estabelecer mudanças significativas nas escolas públicas de ensino médio e essa nova organização curricular pressupõe uma perspectiva de articulação 
Na contramão do ensino médio inovador...

interdisciplinar voltada para o desenvolvimento de conhecimentos, saberes, competências, valores e práticas. Propõe-se estimular novas formas de organização das disciplinas articuladas com atividades integradoras, a partir das interrelaçôes existentes entre os eixos constituintes do ensino médio. Conforme afirma o MEC (2009), do ponto de vista organizacional, não se acrescentariam mecanicamente ao currículo componentes técnicos, ou de iniciação à ciência, ou, ainda, atividades culturais. Tais componentes deverão existir, mas seriam desenvolvidos de forma integrada aos diversos conhecimentos.

Conforme o Parecer CNE/CP n. 11/2009, aprovado em 30/06/ 2009, que examinou a Proposta de Experiência Curricular Inovadora do Ensino Médio elaborada pelo MEC, o Ensino Médio Inovador é um programa específico para inovações curriculares que tem como objetivo a melhoria da qualidade do ensino médio nas escolas públicas, garantindo uma aprendizagem significativa para jovens e adultos através de uma nova organização curricular que pressupõe uma perspectiva de articulação interdisciplinar. Nesse sentido, afirma o documento, propõe estimular novas formas de organização das disciplinas, articuladas com atividades integradoras, a partir das interrelaçôes existentes entre os eixos constituintes do ensino médio, ou seja, o trabalho, a ciência, a tecnologia e a cultura, tendo o trabalho como princípio educativo.

Destacamos que, na contramão dessa perspectiva curricular para o ensino médio, alguns congressistas têm apresentado, na Câmara Federal, projetos de lei que prescrevem a inclusão de disciplinas obrigatórias na educação básica, fragmentando, ainda mais, as áreas de conhecimento. O Conselho Nacional de Educação (CNE) tem se posicionado de forma contrária a essa proliferação de componentes obrigatórios na educação básica por inviabilizar a efetivação de projetos pedagógicos consequentes que busquem a almejada integração disciplinar. Nesse contexto, iniciamos pesquisa no endereço eletrônico da Câmara Federal na tentativa de buscar proposições que contemplassem a inclusão de novas disciplinas no ensino médio a partir do segundo semestre de 2009, após a apresentação pelo MEC e aprovação pelo CNe do Programa Ensino Médio Inovador.

Em nossa investigação realizada no mês de janeiro de 2011, utilizamos como palavras-chave de busca das proposições "currículo do ensino médio" e "disciplinas do ensino médio". Foram encontradas 15 
proposições apresentadas no período compreendido entre os meses de julho de 2009 a dezembro de 2010.

No que se refere à metodologia de análise que nos propomos a realizar sobre os projetos apresentados pelos congressistas, utilizamos a análise retórica, que, como afirma Reboul (1998), em sua função interpretativa, aborda o texto a partir das seguintes questóes: em que ele é persuasivo e quais os seus elementos argumentativos e oratórios? Nesse sentido, não é intenção do presente estudo afirmar que os relatos apresentados têm razão ou não, estão certos ou errados. No entanto, não assumimos uma postura de neutralidade, pois tecemos considerações acerca dos argumentos utilizados, se estes são fortes ou fracos e qual a legitimidade das colocações feitas, procurando apontar que o material de análise, ou o texto estudado, pode sempre ensinar alguma coisa ao leitor, seja pela sua maior ou menor consistência argumentativa.

Conforme afirma Oliveira (2004, p. 3): “a análise retórica busca fundamentalmente responder à questão: em que o discurso é persuasivo? Para tanto, examina as falas e/ou textos com vistas a apontar seus pontos fortes e fracos, isto é, sua maior ou menor capacidade de persuadir".

Convém fazer uma breve problematização sobre os atores envolvidos nesse contexto - o autor (ou autores) dos documentos, denominado orador; e os leitores desses documentos, o auditório. Um discurso tende a persuadir seu leitor de alguma coisa (ou coisas), e esse objetivo que o orador pretende alcançar pode ser imediato ou não, pode gerar efeitos esperados ou mesmo não intencionados. Como afirma Meyer (1993, p. 28), "o orador é simbolizado pelo ethos: a sua credibilidade assenta no seu caráter, na sua honra, na sua virtude, isto é, na confiança que lhe outorgam".

Sempre que argumentamos, o fazemos diante de alguém. Esse alguém, que pode ser um indivíduo, um grupo, uma multidão, chama-se auditório, termo que se aplica até mesmo aos leitores. O auditório, conforme Meyer (op. cit., p. 28) "é representado pelo pathos: para convencer é necessário comovê-lo, seduzi-lo”.

O conhecimento do auditório é vital para o sucesso da argumentação, já que o orador sempre fundamentará seu discurso sobre determinados acordos prévios estabelecidos com o auditório. Quanto 
Na contramão do ensino médio inovador...

melhor se conhece o auditório, maior é o número de acordos prévios que se tem à disposição e, portanto, melhor fundamentada será a argumentação. Acordos prévios são determinadas proposições incontroversas que já se encontram aceitas pelo auditório antes do início do discurso. É sobre estas proposiçôes que o orador baseará seu discurso, procurando transferir a adesão do auditório em relação aos acordos prévios até a tese que apresenta. Estes acordos podem ter naturezas muito diferentes: podem ser fatos de conhecimento público ou notório, podem dizer respeito à hierarquia de valores de uma dada sociedade, podem se referir a auditórios específicos (congregações religiosas, grupos profissionais) e mesmo a auditório universal, que seria o conjunto dos homens razoáveis, ou a expressão de uma determinada imagem do homem construída pelo orador.

O inverso também é verdadeiro porque um dos erros mais comuns em uma argumentação ineficaz é o que se chama de petição de princípio. Esta, afirma Perelman (2000), consiste em supor admitida uma tese que se desejaria fazer admitir pelo auditório. Nesse sentido, a petição de princípio é um erro de argumentação que, uma vez percebido, fragiliza o discurso do orador.

O terceiro componente da análise retórica é o logos, que diz respeito à argumentação propriamente dita do discurso. Ao analisarmos os argumentos do orador, a preocupação da retórica engloba forma e conteúdo, ou seja, o que se fala e como se fala.

\section{Apresentação das proposições}

Em 23 de setembro de 2009, o deputado José Mentor (PT/SP) apresentou o Projeto de Lei (PL) n. 6.099, cuja ementa sugere que "nos estabelecimentos de ensino fundamental, ensino médio e ensino superior torna-se obrigatória a promoção da Educação Ambiental como um componente essencial e permanente da educação nacional”. O deputado enfatiza que

(...) a educação ambiental não será implantada como disciplina específica, uma vez que sua política foi formulada para atuar sob as perspectivas da trans, inter e multidisciplinaridade, perpassando todas as áreas de conhecimento, não podendo constituir-se numa disciplina única. O enfoque holístico, considerando a interdependência entre o meio natural, o 
socioeconômico e o cultural, promove a superação do antropocentrismo e coloca a humanidade no mesmo patamar de igualdade de existência e coexistência com o meio onde habita.

O deputado, apesar de afirmar que não será criada nova disciplina, não explica exatamente do que se trata a "promoção da educação ambiental" nas diferentes etapas da educação básica, bem como na educação superior. Além disso, sua argumentação fica enfraquecida pelo desconhecimento acerca da legislação educacional em vigor, pois ele afirma que a

(...) educação nacional contempla diferentes modalidades de ensino: ensino infantil; ensino fundamental; ensino médio; ensino superior; ensino a distância; educação de jovens e adultos; educação tecnológica e formação profissional; educação especial; educação indígena; educação religiosa e a educação multirracial. Queda-se, porém, quanto à previsão da educação ambiental.

Logo, não fica claro se ele entende a educação ambiental como uma modalidade ou se ele não compreende a diferença, conforme estabelece a LDB n. 9.394/96, entre nível e modalidade de educação e ensino e, nesse sentido, a educação ambiental não poderia ser enquadrada nessa categoria. Destacamos, ainda, que Meio Ambiente é um dos temas transversais que compõem os Parâmetros Curriculares Nacionais (PCN), que engloba, entre outros assuntos, o "ensinar e aprender em educação ambiental”. Nesse sentido, não observamos avanços no projeto do autor, uma vez que propõe algo que está posto desde 1998 nos PCN: tratar a educação ambiental de forma transversal.

Convém, ainda, destacar o uso do termo "holístico" a partir da tese que ele apresenta de que o holismo "promove a superação do antropocentrismo e coloca a humanidade no mesmo patamar de igualdade de existência e coexistência com o meio onde habita". Nesse sentido, o deputado, ao se dirigir ao auditório, pressupõe que sua definição de enfoque holístico é partilhada por todos, portanto incorre em petição de princípio. Segundo Abbagnano (2007), é possível atribuir diferentes significados ao termo holismo, havendo inclusive na tradição da filosofia analítica uma distinção entre holismo metodológico e holismo semântico. A última ação registrada de andamento da proposição indica que ela foi recebida pela Comissão de Educação e Cultura da Câmara em outubro de 2009. 
Na contramão do ensino médio inovador...

Em 6 de outubro de 2009, o deputado pelo PTB/RS Paulo Roberto Pereira apresentou a Indicação n. 5.411, que sugere ao Ministério da Educação a inclusão de lógica e robótica nas diretrizes curriculares do ensino médio. Conforme o autor, "a Lógica auxilia no processo de colocar ordem nas operaçōes da razão e prover instrumentos para o manejo de raciocínios e argumentos que fazem parte de qualquer reflexão (...) e os projetos de robótica levam os alunos a descobrir os fundamentos da tecnologia de uma maneira divertida e ativa".

$\mathrm{O}$ autor agrega o ensino da lógica com o da robótica na tentativa de promover um mecanismo auxiliar no processo de ordenação da razão de forma criativa. Não seria esse o desejo de toda a educação? Fazer com o que o aluno aprenda o que é pertinente, que aprenda a aprender e que o conhecimento faça sentido? $\mathrm{O}$ ensino de filosofia não poderia cumprir esse papel de reflexão sobre os argumentos e sobre o conhecimento? Em nosso entendimento, sim, uma vez que tanto a lógica formal quanto a retórica, ambas estudadas por Aristóteles, são perfeitamente compatíveis com os demais conteúdos filosóficos que figuram nos programas do ensino médio. E quanto ao ensino da robótica? Que procedimentos o autor sugere? Como isso se efetivará no currículo das escolas? Como e por quem será ministrado?

O deputado Regis de Oliveira (PSC/SP) apresentou, em 21 de outubro de 2009, o PL n. 6.262, que institui a obrigatoriedade da disciplina "noçôes sobre os direitos do consumidor" nas grades curriculares do ensino fundamental e ensino médio das escolas públicas e privadas de todo o território brasileiro a partir do $6^{\circ}$ ano do ensino fundamental. Conforme o autor, sua proposta se justifica "de forma que quando chegar o momento de darem início aos atos de consumo possam fazêlos de forma consciente". Um questionamento inicial a partir da fala do autor da proposta é: que momento é esse? Quando é o início do ato de consumo? Será que fazemos algo de forma não consciente? Certamente existe o consumo irresponsável, mas não de forma inconsciente. E, uma vez mais, já não está previsto nos PCN um tema transversal que aborda Trabalho e Consumo? Será necessário criar uma disciplina obrigatória? A última ação disponibilizada sobre o projeto é de que o mesmo se encontra na Comissão de Finanças e Tributação.

O PL n. 6.635 foi apresentado em 16 de dezembro de 2009 pelo deputado Marcos Medrado do (PDT/BA). O autor propõe a "obrigato- 
riedade da inclusão, na grade curricular do ensino médio, do Curso de Primeiros Socorros, a ser ministrado como parte integrante da carga horária exigida para a conclusão da referida modalidade de ensino". Conforme Medrado,

(...) o aluno ou aluna, que cursa o ensino médio, convive diuturnamente com situações que exigem o conhecimento da prática dos primeiros socorros. As estatísticas evidenciam que pouquíssimos jovens estão habilitados a realizar os primeiros socorros. Contudo, as estatísticas também comprovam que a prática correta dos primeiros socorros tem salvado muitas vidas e colaborado de forma significativa com as equipes médico-hospitalares. Portanto, a inclusão obrigatória do Curso de Primeiros Socorros no currículo do ensino médio constitui-se numa iniciativa de relevância social inquestionável.

Inicialmente, é preciso perguntar que estatísticas são essas a que o autor se refere, senão seu discurso passa unicamente por um argumento de autoridade que justifica uma afirmação baseando-se no valor de seu autor, na moralidade, na confiabilidade que ele julga ter por estar exercendo um mandato parlamentar. Como afirmam Perelman e Olbrechts-Tyteca (2002, p. 350), "recorre-se a ele [ao argumento de autoridade] quando o acordo sobre o que se expressa está sujeito a ser questionado". Indagamos se meninos e meninas de todo o país, em todas as escolas brasileiras, estão em condições físicas e psicológicas para tal treinamento e, no caso de um fracasso no atendimento, como serão tratadas as responsabilidades? Seria essa mais uma tarefa para a escola? Treinar jovens socorristas?

Cinco alunos do curso de Direito da Universidade Presbiteriana Mackenzie apresentaram, em 3 de fevereiro de 2010, uma Petição (PET1/2010) no sentido de incluir a disciplina de Introdução ao Estudo do Direito no currículo do ensino médio. Conforme os autores, aprendese no ensino médio a realizar uma conta utilizando logaritmo, mas não é ensinado o que faz um deputado, senador ou prefeito, não é ensinado o que a polícia pode ou não fazer quando aborda um suspeito na rua. Por isso, afirmam, "é necessário implementar as aulas de noções básicas de direito porque o ensino da cidadania é deficiente". O emprego de termos modais como "pode ser", "é preciso que”, “é necessário que" e "deve ser" é comumente encontrado em diferentes discursos e em diferentes contextos e pode, em alguns casos, conferir ao discurso 
Na contramão do ensino médio inovador...

um tom prescritivo, determinando o que deve ser feito ou o que se exige que deva ser feito. Além disso, complementam os autores, "o ensino superior não é acessível a todas as pessoas, e implementando no curso do ensino médio as noções de Direito, o aluno torna-se apto a participar mais ativamente do mercado de trabalho, prestar concursos públicos que exijam conhecimentos técnicos que o concursando só poderia adquirir ao se matricular nos chamados cursinhos preparatórios".

Finalizam afirmando que o estudo do Direito deve ser ensinado em uma nova disciplina no ensino médio, com currículo, aulas e professores próprios. Foi designado relator que apresentou parecer pela rejeição da Petição, sendo aprovado por unanimidade.

Cabe destacar nessa proposição o argumento pragmático de seus autores. Esse tipo de argumento não requer, para ser aceito pelo senso comum, nenhuma justificação, ele permite concluir pela superioridade de uma conduta, partindo da utilidade de suas consequências, e é apresentado como uma simples pesagem de alguma coisa por meio destas consequências. Logo, atribuem alta relevância ao estudo de Direito e, portanto, ele deve ser ensinado nas escolas de nível médio. Esse argumento, na verdade, quer estabelecer um juízo de valor, mostrar o valor do efeito a partir do valor da causa. Faltou, porém, firmar com o auditório um acordo acerca dessa importância. Quem decidiu isso e quem atribuiu tanta relevância a esse tema e não a tantos outros?

Em 8 de fevereiro de 2010, o deputado Francisco Rossi (РMDB/ SP) apresentou o PL n. 6.773, que determina a inclusão, "no currículo escolar a partir do segundo grau, do ensino da disciplina denominada Organização dos Poderes, cujo conteúdo e programa serão elaborado pelo MEC". Conforme o autor, "a disciplina será ministrada durante um ano para alunos que cursarem o segundo grau, em carga horária mínima de 1 (uma) hora semanal, por docentes que deverão comprovar o competente preparo".

Conforme a justificativa, essa disciplina se propõe a estudar as premissas da democracia, a gestão dos Poderes e o efetivo cumprimento legitimamente estabelecido pela Constituição Federal brasileira. Rossi afirma que "o fato é que se tem pouco ou nenhum preparo para a vida. Não obstante o torrencial recebimento de informações proporcionado pelos mais diversos meios, certo é que os jovens perecem de 
um pressuposto fundamental de discernimento inerente ao desenvolvimento político do país". Nesse sentido, finaliza, "o objetivo precípuo da iniciativa é capacitar o cidadáo para sua efetiva participação junto à sociedade e consequentemente às esferas do Poder".

A proposição do autor permite uma série de questionamentos. Inicialmente, será mesmo necessária uma hora semanal durante 200 dias letivos para contemplar os conteúdos que o autor menciona? Como ter também certeza de que os jovens não possuem discernimento quanto ao desenvolvimento político do país? Em que estudos ou pesquisas o deputado se baseia para fazer semelhante afirmação? E o que ele chama de preparo competente? Os professores não são preparados nem competentes sobre o tema? E, adicionalmente, o que o deputado quer dizer quando afirma que se tem pouco ou nenhum preparo para a vida? Afinal, como se prepara para a vida, senão vivendo? $\mathrm{E}$, por fim, não podemos deixar de destacar a utilização desatualizada do termo segundo grau. Já foi designado relator e nenhuma emenda foi apresentada ao projeto, que se encontra na Comissão de Educação e Cultura da Câmara.

Bruno Rodrigues (PSDB/PE) apresentou, em 24 de fevereiro de 2010, o PL n. 6.849, que torna obrigatória a inclusão da disciplina Educação Nutricional e Hábitos Alimentares em todas as instituições de ensino do país e passa a integrar o currículo do ensino fundamental e médio. O projeto encontra-se na Comissão de Seguridade Social e Família. Conforme o documento, o conteúdo programático da disciplina será ministrado, preferencialmente, por profissionais com formação em Nutrição e ficam obrigadas as instituições de ensino do país a contratarem pelo menos 1 (um) nutricionista que ficará responsável pelo gerenciamento e planejamento das refeiçóes e merendas escolares distribuídas aos alunos. De acordo com a justificativa do autor, a promoção de saúde entre crianças maiores de cinco anos de idade habitualmente não é prioridade nas políticas de saúde oficiais, em particular no ambiente escolar, e a implementação da educação nutricional como obrigatória no ensino fundamental evidencia-se como uma política pública premente.

A proposta esbarra em alguns obstáculos. Inicialmente, o fato de a disciplina ser ministrada por um profissional da área de Nutrição e a exigência de um profissional por escola, o que demandará contratações e concursos, implicando custos elevados. É importante salientar que já 
Na contramão do ensino médio inovador...

existe o Programa Nacional de Alimentação Escolar, coordenado pelo Fundo Nacional de Desenvolvimento da Educação (FNDE). Conforme o programa, o cardápio escolar, sob responsabilidade dos estados, do Distrito Federal e dos municípios, deve ser elaborado por nutricionista habilitado. Nesse sentido, já existe uma ação coordenada de oferta de merenda escolar, o que fragiliza a argumentação do parlamentar, para o qual as políticas de saúde em relação às crianças maiores de cinco anos não são prioritárias. Por outro lado, o tema pode (se já não é) ser abordado por várias disciplinas do currículo nas diferentes faixas etárias.

A Comissão de Educação e Cultura apresentou, em 8 de abril de 2010, a Indicação n. 6.303, que sugere ao ministro de Estado da Educação a inclusão da disciplina Empreendedorismo nos currículos do ensino fundamental, médio, educação profissional e educação superior. Conforme o documento, o deputado Luiz Carlos Hauly (PSDB/PR) apresentou projeto de lei com o objetivo de incluir a referida disciplina e afirmou que uma das grandes falhas do ensino brasileiro, sobretudo o de educação superior, é a completa ausência de discussões e investimentos sobre o tema empreendedorismo. Conforme Hauly, "num país como o nosso, em que a falta de emprego é patente, torna-se importante que se invista no ensino do empreendedorismo, para que o mesmo seja alternativa para se entrar no mercado de trabalho cada vez mais competitivo".

Por meio desta Indicação, a Comissão manifestou apoio à iniciativa do deputado, sugerindo a inclusão da referida disciplina nos currículos da educação básica e superior. Os argumentos utilizados pelo autor acabam enfraquecidos pelo uso de um lugar comum (a patente falta de emprego) que pode justificar tanto a inserção de "empreendedorimo" quanto, por exemplo, de "combate ao desemprego", de "políticas de emprego" ou qualquer outra disciplina afim. Seria, uma vez mais, o inchamento do currículo disciplinar a salvação para essa problemática?

Em outro momento (24 de maio de 2010), a Comissão de Educação e Cultura da Câmara apresentou nova Indicação (n. 6.426). Após apreciar o PL n. 4.952, de 2009, de autoria do deputado Nelson Bornier (PMDB/RJ), cujo objetivo era instituir, no âmbito das escolas das redes pública e privada de todo o país, o "Programa Segurança no 
Trânsito", a Comissão de Educação e Cultura da Câmara dos Deputados, reconhecendo o mérito da proposta, rejeitou a forma com que foi apresentada - projeto de lei - e deliberou pelo seu encaminhamento como Indicação ao Ministério de Educação, nos termos do parecer do relator, deputado Átila Lira (PSB/PI).

A Indicação procurou ratificar a importância do tema, que "deve ser trabalhado de maneira interdisciplinar, no contexto das diferentes disciplinas do currículo escolar ou na forma de um programa específico, como parte da política educacional do atual governo". A partir de uma breve exposição sobre as estatísticas mundiais de mortes por acidentes automobilísticos, com destaque para a situação crítica do Brasil nesse cenário, o documento aponta que "faz-se necessária a obrigatoriedade da aplicação dessas ações aos alunos matriculados na última série do ensino médio, objetivando incutir nos jovens que estão, por suposição, na iminência de se habilitarem, costumes condizentes com os princípios da direção defensiva”. Logo, ao assinar a Indicação, o presidente da Comissão sugere que o MEC analise a viabilidade técnica e educacional de se implantar o "Programa Segurança no Trânsito" nas escolas de ensino médio das redes pública e privada em todo o país.

De certo que os índices de acidentes no trânsito no país são alarmantes, mas, novamente, insistimos na estratégia utilizada pelos legisladores: será que todo assunto relevante deve virar assunto escolar? Será que a inclusão de novas disciplinas ou o inchamento dos programas das disciplinas já existentes no currículo irá possibilitar tamanha reforma na educação brasileira, como desejam esses parlamentares? E, ainda, será que mais uma vez não estariam os congressistas depositando na escola uma responsabilidade que deveria ser compartilhada por todos?

O PL n. 7.415, de autoria do deputado Gilmar Machado (PT/ MG), foi apresentado em 27 de maio de 2010 e propõe que "o ensino da Geografia constituirá conteúdo obrigatório em todas as séries do ensino médio, sendo que o ensino da Geografia levará em conta o conhecimento do mundo físico e natural e da realidade social e política, especialmente do Brasil". Conforme a justificativa, a disciplina de Geografia sempre foi reconhecida como sendo de suma importância para a formação de cidadãos éticos, críticos, sujeitos e protagonistas. Logo, afirma Machado, 
(...) é determinante para a formação do caráter dos cidadãos por ser mais um elemento auxiliar na formação do pensamento crítico dos jovens, propiciando melhores condiçôes para o exercício da cidadania, bem como a sua formação plena enquanto ser humano. Assim, não restam dúvidas de que a inclusão da disciplina de Geografia no currículo do ensino médio das escolas do país acarretará uma melhor formação dos adolescentes, em razão do desenvolvimento do senso crítico, ética e cidadania.

No prazo regimental, foi apresentada uma emenda pela deputada Fátima Bezerra (PT/SP) que propõe a substituição da expressão "conteúdo obrigatório" por "disciplina obrigatória". O relator do PL, deputado Antonio Carlos Biffi (PT/Ms), afirma em sua análise que os conteúdos relacionados à Geografia estão inseridos não apenas nos currículos do ensino médio, mas, também, do ensino fundamental e que determinar sua obrigatoriedade apenas para as três séries do ensino médio seria "um retrocesso na legislação". Conforme o relator, considerando que não há a necessidade de determinar o "formato de disciplina para incluir um componente curricular obrigatório na base nacional, parece-me que mais adequado seria não acatar a emenda apresentada pela deputada Fátima Bezerra". Seu voto foi pela aprovação do PL n. 7.415, de 2010, em que "o ensino da Geografia constituirá componente curricular obrigatório e levará em conta o conhecimento do mundo físico e natural e da realidade social e política, especialmente do Brasil”.

A pergunta que emerge a partir da leitura desse projeto é: já não é ensinado o conteúdo da Geografia, seja como disciplina ou como área de conhecimento? Qual a necessidade de um projeto de lei para impor a criação de uma disciplina obrigatória?

Eduardo Cunha (PMDB/RJ) apresentou, em 8 de junho de 2010, o PL n. 7.450, que dispõe sobre "a obrigatoriedade da inclusão da matéria de estudo crítico Leitura e Educação para as Mídias nas grades curriculares dos ensinos fundamental e médio nas escolas públicas e privadas da rede de ensino do país".

Conforme o autor, a matéria "prevê o ensino de conteúdos cujo objetivo é oferecer aos estudantes a possibilidade de análise crítica do que a mídia expõe, seja pelos canais de TV e rádio ou por veículos impressos, sejam estes conteúdos noticiosos, publicitários ou de entretenimento". Dessa maneira, "os estudantes poderão entender como 
funcionam os canais midiáticos e debater, sob o viés ético, moral e, sobretudo, constitucional, as diversas características, positivas ou negativas, que estes canais empregam em seus conteúdos".

Cunha propõe ainda a "revisão da grade curricular do curso superior de Comunicação Social" e a criação de "cursos de Licenciatura para os futuros jornalistas, publicitários e relações públicas que, porventura, ingressem na carreira de professores da matéria Leitura e Educação para as Midias". O deputado acredita que, com a implantação dessa disciplina nas escolas brasileiras, "o ensino de toda a grade contará com um aluno mais interessado para todas as matérias da grade curricular. A nova proposta determinará um novo rumo para a educação no país, com reflexos positivos em todos os segmentos sociais". Já foi designado relator, o projeto encontra-se na Comissão de Educação e Cultura da Câmara e não foram apresentadas emendas.

Concordamos com o autor acerca da importância da análise sobre o que é divulgado pela imprensa e ressaltamos que o debate é fundamental. No entanto, a perspectiva apontada por Cunha de criar uma disciplina exclusiva para esse debate acaba por limitar os espaços e o tempo que a escola poderia utilizar para as discussões. Tendo lecionado por mais de dez anos no ensino médio antes de ingressar na docência universitária, um de nós constatou que muitos professores de Língua Portuguesa, de História e de Geografia já faziam uso, em fins da década de 80 do último século, dos seus tempos em sala de aula para debater programas da televisão e matérias publicadas em jornais, sendo muito provável que hoje em dia incluam também materiais veiculados na internet. Por isso, questionamos se seria realmente necessária a criação de uma nova licenciatura para a oferta dessa disciplina. Além disso, não seria esperar demais que uma disciplina "determine um novo rumo para a educação no país"?

Ronaldo Caiado (DEM/GO) apresentou, em 4 de agosto de 2010, o PL n. 7.746, que propõe a obrigatoriedade do ensino de noções técnicas, não partidárias, de Ciência Política no ensino médio de modo a tornar os eleitores mais capacitados para entenderem a realidade política. $\mathrm{O}$ autor propõe o estudo dos seguintes temas: representação política; história do voto no Brasil; atribuições dos cargos políticos; definição das atribuições dos poderes Executivo, Legislativo e Judiciário, entre outros temas. 
Conforme o deputado, "apesar da inclusão do ensino de Filosofia e Sociologia como disciplinas obrigatórias em todas as séries do ensino médio, estas matérias não abarcam algumas noçôes imprescindíveis para a compreensão da realidade política brasileira presentes na área de estudo da Ciência Política”. O projeto foi encaminhado às Comissões de Educação e Cultura e Constituição e Justiça e de Cidadania. Não concordamos com o deputado acerca da necessidade de uma disciplina que trabalhe ao longo do ensino médio os conteúdos propostos por ele. Muitos dos assuntos mencionados já são trabalhados em História e pensar a realidade política brasileira não é responsabilidade de uma única disciplina, mas de toda a escola e seus profissionais.

Em 7 de dezembro de 2010, Vicentinho Alves (PR/TO) apresentou o PL n. 7.990, que torna obrigatória nos estabelecimentos de ensino fundamental e médio, públicos e privados, a disciplina de Direito Constitucional aos alunos regularmente matriculados. Segundo o documento, ministrarão essa disciplina os professores habilitados em Ciências Humanas, Sociais, Políticas e Jurídicas ou professores habilitados em Direito Constitucional. Em sua justificativa, o deputado argumenta que a inclusão da matéria será de suma importância para os jovens:

(...) se com 16 anos eles podem votar, porque não saber o que é uma lei maior, ter o mínimo de conhecimento do que realmente está escrito na Constituição Federal, o porquê de estar votando, tendo conhecimento ainda sobre nacionalidade, cidadania, direitos e garantias fundamentais, direitos sociais como, por exemplo, a ter um trabalho e outras questôes relevantes como e quando é aplicada a pena de morte, prisão perpétua, direitos dos índios, entre outras questôes de extrema importância que todos os novos jovens cidadãos devem saber. O objetivo primordial é levar o cidadão a um entendimento de um texto legal, saber o que é uma Constituição, uma Lei, um Decreto, e, óbvio, conhecer o grau de hierarquia entre todas estas normas para adequá-las ao nosso cotidiano e avaliar os reflexos jurídicos que são produzidos a cada ato ou omissão que viermos a praticar.

O projeto encontra-se na Comissão de Educação e Cultura. Conforme a argumentação do autor, se o jovem já pode votar, então fica, por si só, justificada a oferta de uma disciplina sobre direito 
constitucional. Se esse argumento de sucessão pelo vínculo causal ("se isto, então aquilo") for considerado sem exame crítico, enxertará uma série de novas disciplinas na escola, contemplando os mais variados temas: educação sexual, educação para o trânsito, ética, cidadania, entre tantos outros elencados nos projetos analisados.

Por fim, o último documento encontrado no período tomado como referência é a Indicação n. 6.734, apresentada em 21 de dezembro de 2010 pela Comissão de Finanças e Tributação, que sugere a inclusão na grade de ensino do nível médio de uma matéria com o objetivo de promover a educação financeira dos futuros cidadãos. Conforme o documento,

(...) a melhoria do nível de renda da população brasileira nos últimos anos acarretou o acesso de grande parcela de brasileiros das classes econômico-sociais $\mathrm{C}$ e $\mathrm{D}$ ao sistema bancário, cujos instrumentos e facilidades desconheciam ou deles tinham pouco conhecimento. Ademais, eles incorporaram rapidamente novos hábitos de consumo, devido, em parte, à crescente oferta de crédito sob diversas formas, como os empréstimos consignados em folha de pagamento, o microcrédito orientado, o cartão de crédito, o financiamento habitacional, entre outros. A falta de conhecimento mínimo daquelas pessoas em finanças pessoal, que lhes permitisse perceber as vantagens e desvantagens dos instrumentos financeiros a que passaram a ter acesso, levou-as a elevado endividamento e a posterior inadimplemento.

Os autores da Indicação acreditam ser necessário assegurar educação financeira aos jovens estudantes brasileiros como parte do seu preparo para o exercício da vida econômica e da cidadania e que isso será possível através da inclusão da disciplina que propõem na grade curricular do ensino médio. Assim, afirma o deputado Pepe Vargas (PT/ RS), presidente da Comissão de Finanças e Tributação da Câmara dos Deputados, "a juventude que irá se deparar com as práticas das instituições financeiras e com instrumentos de crédito que serão oferecidos estará preparada para tomar decisões racionais e para avaliar a conveniência entre poupar e antecipar consumo, um dos pilares para um desenvolvimento duradouro".

Assim como os outros projetos, a Indicação feita pela Comissão parte da hipótese da ignorância da população acerca das questóes financeiras, cabendo novamente à escola dar conta de abordar esse conteúdo. 
Na contramão do ensino médio inovador...

\section{Considerações finais}

Conforme o texto da Emenda Constitucional n. 59/2009, a partir de 2011 o ensino no Brasil passa a ser obrigatório dos 4 aos 17 anos de idade. Nesse sentido, com a obrigatoriedade de oferta e de matrícula dessa etapa, as escolas brasileiras poderão vir a receber um número maior de matrículas e a etapa final da educação básica terá grandes desafios pela frente: tornar-se atraente, pertinente e, como deseja o MEC, inovadora. Nos últimos dez anos, apesar da meta estabelecida pelo Plano Nacional de Educação para o período 2001-2010 de oferecer, no ensino médio, vagas correspondentes a $100 \%$ da demanda, chegamos ao final de 2008 com somente $50 \%$ dos jovens entre 15 e 17 anos frequentando a última etapa da educação básica.

O novo Plano Nacional de Educação (2011-2020) apresenta a meta de universalizar, até 2016, o atendimento escolar para toda a população de 15 a 17 anos e elevar, até 2020 , a taxa líquida de matrículas no ensino médio para $85 \%$ nesta faixa etária. A proposta do documento para esta etapa do ensino visa institucionalizar o programa nacional de diversificação curricular, a fim de incentivar abordagens interdisciplinares estruturadas pela relação entre teoria e prática, discriminando-se conteúdos obrigatórios e conteúdos eletivos articulados em dimensões temáticas tais como ciência, trabalho, tecnologia, cultura e esporte. Observa-se, nesse contexto, que a direção que o MEC pretende dar ao ensino médio contrasta com as propostas apresentadas pelos congressitas, isto é, o MEC quer inovar, abordar de forma interdisciplinar os conteúdos ensinados, ao passo que alguns deputados querem fragmentar e disciplinarizar ainda mais o conhecimento e os conteúdos escolares.

Segundo as palavras de Kuenzer (2010, p. 853), "com relação ao ensino médio, com suas históricas mazelas, o que há de novo a pontuar para o novo Plano, senão o enfrentamento das dificuldades que vêm sendo apontadas tanto pela sociedade civil quanto pelo governo, desde a década de 1980?”. A autora destaca ainda que, em relação à organização curricular do ensino médio, é preciso superar as propostas pedagógicas academicistas, centradas em disciplinas fragmentadas.

Como afirma Oliveira (2009, p. 549), na concepção pedagógica apresentada nas proposiçōes dos congressistas, "é como se o currículo 
escolar se compusesse de fora para dentro das escolas pelo somatório de disciplinas sem necessária conexão entre si, mas pretensamente importantes para o bom funcionamento da sociedade".

Destacamos a nota técnica publicada por José Maria de Almeida Junior (2003) acerca de proposições sobre criação de disciplinas escolares e atividades curriculares. Conforme o consultor, tais proposições não são da competência do Poder Legislativo, mas sim das próprias escolas, de suas comunidades e dos conselhos de Educação (Federal, Estaduais e Distrital), com orientação do Poder Executivo pela via do Ministério da Educação.

Apesar dos projetos analisados insistirem na inclusão de disciplinas obrigatórias, encontramos dois documentos que ressaltam a necessidade da implantação e do debate sobre a proposta Ensino Médio Inovador. A deputada Vanessa Grazziotin (PC do B/AM) apresentou em 26 de agosto de 2009 a Indicação n. 5.194, que sugere ao ministro da Educação providências no sentido de implantar o Projeto Ensino Médio Inovador em todas as capitais e que, pelo menos, entre as cem escolas que participarão do projeto, estejam as das capitais do país. O deputado Iran Barbosa (PT/SE) apresentou, em 10 de março de 2010, o Requerimento n. 296, que propõe a realização de audiência pública para debater o ensino médio inovador. Conforme o autor, "é no ensino médio que estão concentradas as grandes dificuldades no processo de escolarização e onde o país evidencia a sua distância da universalização do ensino". Diante da importância do Programa e da nova perspectiva de organização curricular e superação de desafios, Barbosa propõe que sejam convidadas algumas autoridades ${ }^{1}$ para detalharem os aspectos do programa, opinarem a respeito do projeto e relatarem experiências com a implantação do ensino médio inovador.

Concluímos que falta diálogo entre o Executivo e o Legislativo no que diz respeito ao campo da educação e ao objeto de análise deste artigo, que é a proposta de construção de um modelo para o ensino médio mais adequado à nova realidade do jovem brasileiro que vive em "relações sociais e produtivas marcadas pela exclusão, pela ausência de projeto de futuro, pela complexidade tecnológica e dos meios de comunicação, pela flexibilidade, pela instabilidade, pela intensificação" (Kuenzer, 2010, p. 869). E não pode haver diálogo sem um entendimento mínimo entre os interlocutores. 
Na contramão do ensino médio inovador...

\section{Nota}

1. Carlos Artexes Simões, diretor de Concepções e Orientações Curriculares para a Educação Básica da Secretaria de Educação Básica do Ministério da Educação; Yvelise Freitas de Souza Arco-Verde, presidente do Conselho Nacional de Secretários de Educação (CONSED) e secretária de Estado da Educação do Paraná; Clélia Brandão Alvarenga Craveiro, presidente do Conselho Nacional de Educação (CNE) e Integrante da Câmara de Educação Básica do mesmo Conselho; Roberto Franklin de Leão, presidente da Confederação Nacional dos Trabalhadores em Educação (CNTE).

\section{Referências}

ABBAGNANO, N. Dicionário de filosofia. São Paulo: Martins Fontes, 2007.

ALMEIDA JUNIOR, J.M.G. Proposiçōes sobre curriculo escolar em qualquer modalidade educacional ou nivel de ensino. Nota técnica. Brasília, DF: Consultoria Legislativa; Câmara dos Deputados, jun. 2003.

BRASIL. Câmara dos Deputados. Indicação n. 5.411 de 2009. Brasília, DF: Câmara dos Deputados, 6 out. 2009.

BRASIL. Câmara dos Deputados. Indicação n. 6.303 de 2010. Brasília, DF: Câmara dos Deputados, 8 abr. 2010.

BRASIL. Câmara dos Deputados. Indicação n. 6.426 de 2010. Brasília, DF: Câmara dos Deputados, 24 maio 2010.

BRASIL. Câmara dos Deputados. Indicação n. 6734 de 2010. Brasília, DF: Câmara dos Deputados, 21 dez 2010.

BRASIL. Câmara dos Deputados. Petição PET-1/2010. Brasília, DF: Câmara dos Deputados, 3 fev. 2010.

BRASIL. Câmara dos Deputados. Projeto de Lei n. 6.099 de 2009. Brasília, DF, Câmara dos Deputados, 25 ago./23 set. 2009.

BRASIL. Câmara dos Deputados. Projeto de Lei n. 6.262 de 2009. Brasília, DF: Câmara dos Deputados, 21 out. 2009.

BRASIL. Câmara dos Deputados. Projeto de Lei n. 6.635 de 2009. Brasília, DF: Câmara dos Deputados, 16 dez 2009. 
BRASIL. Câmara dos Deputados. Projeto de Lei n. 6.773 de 2010. Brasília, DF: Câmara dos Deputados, 8. fev. 2010.

BRASIL. Câmara dos Deputados. Projeto de Lei n. 6.849 de 2010. Brasília, DF: Câmara dos Deputados, 24 fev. 2010.

BRASIL. Câmara dos Deputados. Projeto de Lei n. 7.415 de 2010. Brasília, DF: Câmara dos Deputados, 27 maio 2010.

BRASIL. Câmara dos Deputados. Projeto de Lei n. 7.450 de 2010. Brasília, DF: Câmara dos Deputados, 8 jun. 2010.

BRASIL. Câmara dos Deputados. Projeto de Lei n. 7.746 de 2010. Brasília, DF: Câmara dos Deputados, 4 ago. 2010.

BRASIL. Câmara dos Deputados. Projeto de Lei n. 7.990 de 2010. Brasília, DF: Câmara dos Deputados, 7 dez. 2010.

BRASIL. Ministério da Educação. Conselho Nacional de Educação. Conselho Pleno. Parecer CNE/CP n. 11/2009, proposta de experiência curricular inovadora do Ensino Médio, aprovado em 30/06/2009.

BRASIL. Ministério da Educação. Secretaria de Educação Básica. Ensino Médio Inovador. Brasília, DF: MEC/SEB, 2009.

KUENZER, A.Z. O ensino médio no Plano Nacional de Educação 2011-2020: superando a década perdida? Educação \& Sociedade, Campinas, v. 31, n. 112, p. 851-873, 2010.

MEYER, M. Questões de retórica: linguagem, razão e sedução. Lisboa: Ediçōes 70, 1998.

MEYER, M.; CARRILHO, M.M.; TIMMERMANS, B. História da retórica. Lisboa: Temas \& debates, 2002.

OLIVEIRA, R.F. A agenda do Legislativo Federal para as políticas curriculares no Brasil (1995-2007). Educação \& Pesquisa, São Paulo, v. 35, n. 3, p. 541-555, set./dez. 2009.

OLIVEIRA, R.J. O conceito de verdade como tema de problematização curricular. In: COLÓQUIO LUSO-BRASILEIRO SOBRE QUESTÓES CURRICULARES, 2., 2004, Rio de Janeiro. Currículo: pensar, inventar, diferir. Rio de Janeiro, 2004a. Trabalho publicado em meio digital. 
Na contramão do ensino médio inovador...

PERELMAN, C. Retóricas. São Paulo: Martins Fontes, 2000.

PERELMAN, C.; OLDBRECHTS TYTECA, L. Tratado da argumentação. São Paulo: Martins Fontes, 2002.

REBOUL, O. Introdução à retórica. São Paulo: Martins Fontes, 1998.

SILVA, M.R. Tecnologia, trabalho e formação na reforma curricular do ensino médio. Cadernos de Pesquisa, São Paulo, v. 39, n. 137, p. 441-460, maio/ago. 2009.

Recebido em 24 de março de 2011.

Aprovado em 28 de abril de 2011. 